\title{
Study of Reproducibility of Rapd Markers in Rice Cultivars
}

\author{
Abdul Momin Raufi* \\ Lecturer in Department of Biology, Education Faculty, Jawzjan University, Sheberghan, Afghanistan \\ *Corresponding Authors: Abdul Momin Raufi, Lecturer in Department of Biology, Education Faculty, \\ Jawzjan University, Sheberghan, Afghanistan
}

\begin{abstract}
The development and use of molecular markers for the detection and exploitation of DNA polymorphism is one of the most significant developments in the field of molecular genetics. Due to advances in molecular biology techniques, large numbers of highly informative DNA markers have been developed for the identification of genetic polymorphism. Random amplified polymorphic DNA (RAPD) technique based on the polymerase chain reaction (PCR) has been one of the most commonly used molecular techniques to develop DNA markers. But RAPD is infamous for its non-reproducibility because of various factors. So, in this work, an attempt was made to study its reproducibility in three Oryza sativa (Rice) varieties. Three different primers were tested, of which two reproducible RAPD primers were chosen. To ascertain their reproducibility, PCR was repeated three times for molecular profiling of random Restorer lines and confirmed their reproducibility.
\end{abstract}

Keywords: RAPD markers, rice cultivars, reproducibility.

\section{INTRODUCTION}

Rice is a monocot plant ( $\mathrm{n}=12)$, belongs to the family 'Graminae/ poaceae' and subfamily 'orazoidea'. Its genome is about $430 \mathrm{Mb}$ and includes two important species $O$. sativa and $O$. Glaberrinia. Rice is the staple food for most of the communities around the world. Besides being staplefood it also has been found to prevent Epilepsy, Chronic headache, Rheumatism, paralysis. The four known varieties of the rice include Indica, Japonica, Aromatic and glutinous. The five top rice producing nations are India, Vietnam, Thailand, Pakistan and USA. The cultivated rice plant (Oryza sativa L.) belongs to the tribe Oryzeae under the sub-family Pooideae in the grass family Gramineae (Poaceae).

Genetic diversity of rice has been assessed using RAPD, ISSR, AFLP, STMS and recently SNP markers. Most studies have focused on specific groups of genotypes such as aromatic, landraces, regions etc. while efforts are limited for assessment of overall diversity. Rice genetic diversity assessed so far suggests a broad genetic base in India. Genotype specific pattern have been developed particularly for the elite Basmati types for use in trade and commerce. Commercial cultivars are genetically homogenous while the landraces studied revealed composite genetic structure. There is a need to constitute core and mini core collections based on 80,000 accessions preserved in gene bank, validate them and characterize them for genetic and phenotypic diversity.

It is extremely difficult to find a molecular marker which would meet all the above criteria. A wide range of molecular techniques is available that detects polymorphism at the DNA level. Depending on the type of study to be undertaken, a marker system can be identified that would fulfil at least a few of the above characteristics (Weising et al., 1995). RAPD markers were found to be easy to perform by different laboratories, but reproducibility was not achieved to a satisfactory level (Nitish et al., 2010) and, therefore, the method was utilized less for routine identifications. RAPD marker diversity was used also applied for diversity studies within and among some other Asteraceae species (Senthilkumar and Subramiam, 2000). Hybrid rice possesses a yield advantage of 10- 20\% over the best inbred varieties. Its commercial production has recently been attempted in many countries, following its success in China (Nandakumar et al., 2004).

In this work, the idea was to check the reproducibility of the RAPD markers in Rice cultivars. For that, ten different varieties of the rice were selected, belonging to different lines. The DNA was isolated, and with the seven different RAPD primers, the RAPD was run. Out of these, the two Primers were found to be reproducible and their reproducibility was further tested by amplifying them with random rice cultivars. The results were positive i.e. they were found to be reproducible. 


\section{Materials AND Methods}

\subsection{Plant Material used}

Three different leaf samples of the different varieties (AFM 19A1, AFM 19A2, AFM 19A3) of the rice (Oryza sativa) plant with cytoplasmic male sterile cell line were acquired.

\subsection{Genomic DNA Isolation and Identification of Reproducible RAPD Markers}

Genomic DNA form the selected rice varieties were isolated by Cetyl Tri Methyl Ammonium Bromide (CTAB) method. It is important to note that the RAPD markers are notorious for not able to reproduce the bands. So in order to make sure that the marker is reproducible, three different markers were each tested three times and the reproducibility was checked.

Table1. Primers used in the study

\begin{tabular}{|l|l|}
\hline Primer name & Sequence \\
\hline OPF-O3 & CCTGATCACC \\
\hline OPB-01 & GTTTCGCTCC \\
\hline OPB-12 & CCTTGACGCA \\
\hline
\end{tabular}

Table2. RAPD PCR Profile

\begin{tabular}{|c|l|l|c|}
\hline Step & Action & Temperature & Time \\
\hline $\mathbf{1}$ & Initial Denaturation & $94^{\circ} \mathrm{C}$ & $5 \mathrm{~min}$ \\
\hline $\mathbf{2}$ & Denaturation & $94^{\circ} \mathrm{C}$ & $30 \mathrm{sec}$ \\
\hline $\mathbf{3}$ & Annealing & $55^{\circ} \mathrm{C}$ & $30 \mathrm{sec}$ \\
\hline $\mathbf{4}$ & Extension & $72^{\circ} \mathrm{C}$ & $1 \mathrm{~min}$ \\
\hline $\mathbf{5}$ & Go To step 2 Repeat 44 times & & - \\
\hline $\mathbf{6}$ & Final Extension & $72^{\circ} \mathrm{C}$ & $5 \mathrm{~min}$ \\
\hline $\mathbf{7}$ & On Hold & $4^{\circ} \mathrm{C}$ & - \\
\hline
\end{tabular}

\section{RESULTS AND DISCUSSION}

\section{Genomic DNA isolation}

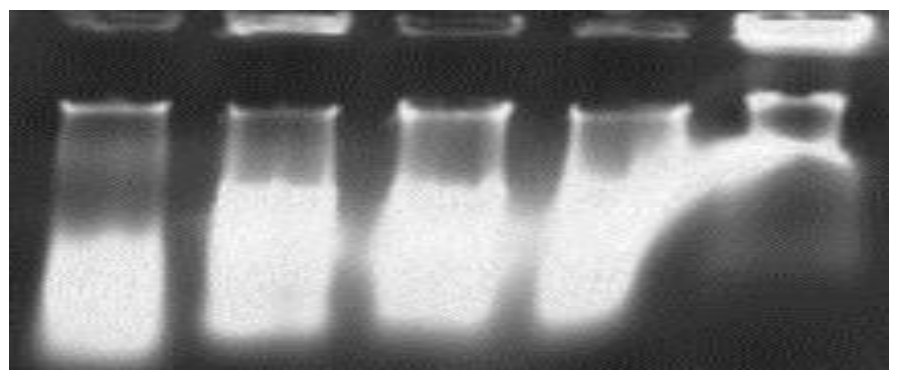

Fig1(a). Genomic DNA isolation

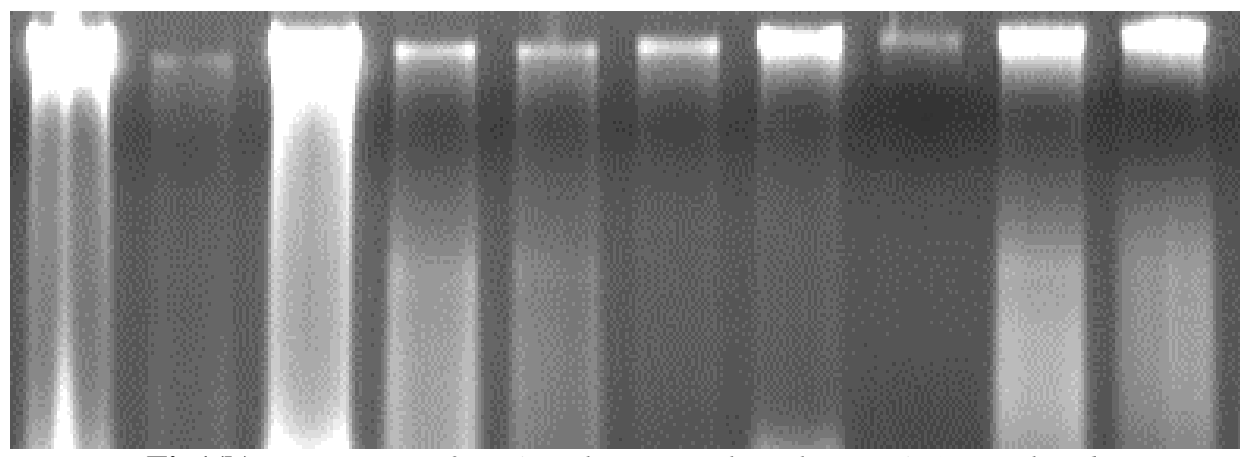

Fig1(b). Repetition of DNA isolation until quality DNA Got isolated.

The DNA isolated needed for RAPD could be afforded to be of very less quantity but of good quality, without any impurity like RNA or phenols. After repeating the isolation protocol twice, good quantity of fine quality DNA was isolated. DNA was also isolated during the molecular profiling of random varieties of AFM 19A. This was done using the method described above.

Identification of reproducible RAPD markers for genotyping 
All the seven RAPD markers were each tested three times in CMS lines. Keeping in mind the nonreproducibility of the RAPD, the protocols were followed rigorously, besides that certain techniques were standardized. The results are given below:

\section{Primer OPF03}

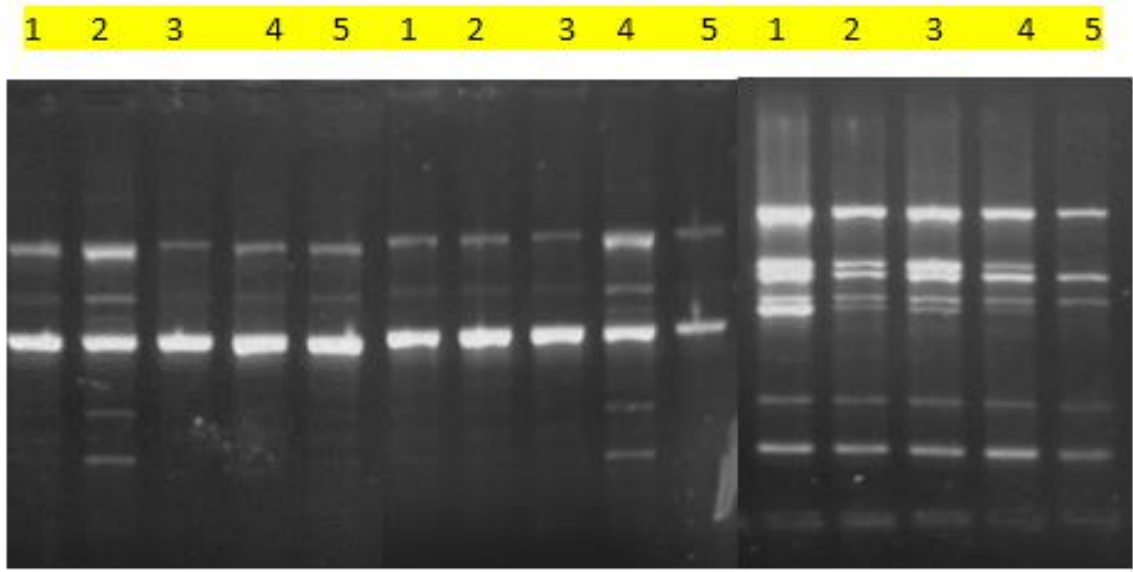

Fig2. Geldoc image of Restorer line RAPD bands using OPF-03 primers performed three different times. It showed low reproducibility. On the third test it showed abnormal pattern

\section{Primer B1}

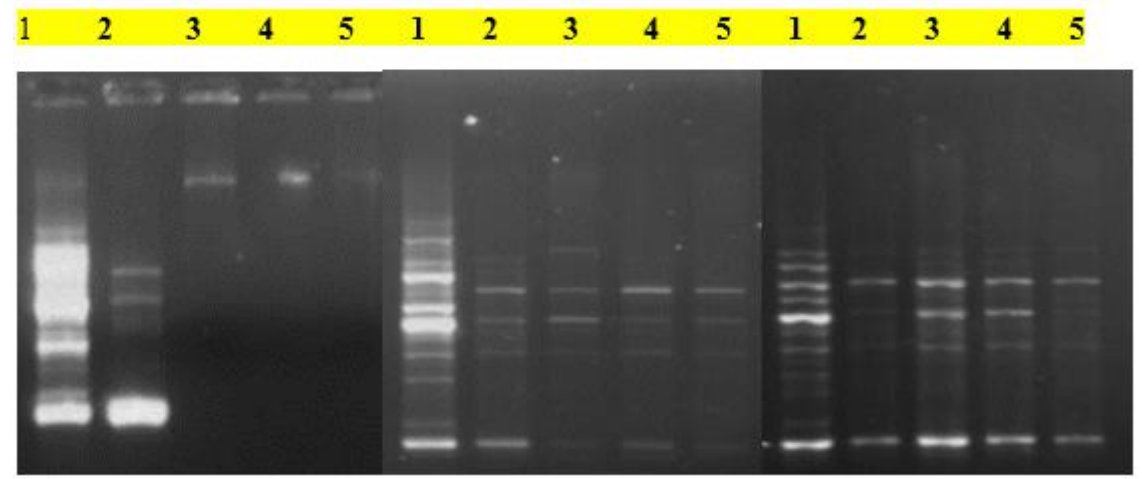

Fig3. Geldoc image of Restorer line RAPD bands using OPB-01 primers performed three different times. The results were reproducible. Some wells didn't amplify properly so the reproducibility test inconclusive.

\section{Primer OPB12}

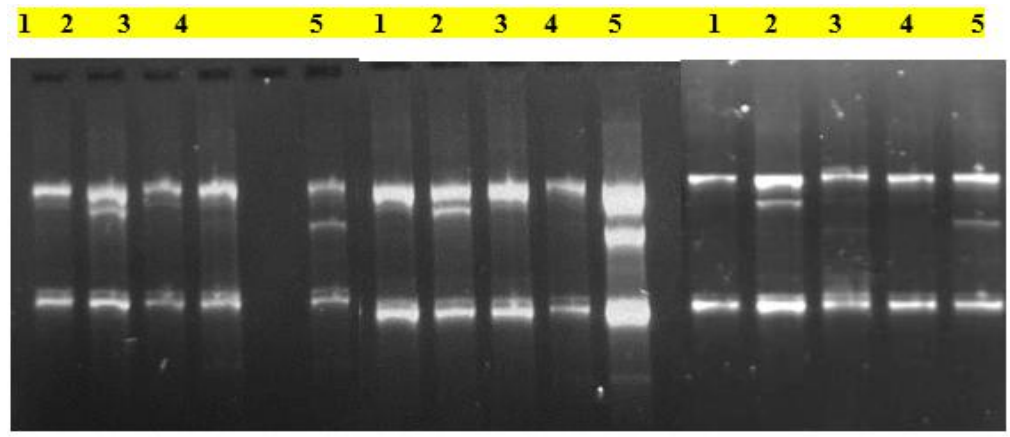

Fig4. Geldoc image of Restorer line RAPD bands using OPB-12 primers performed three different times. The results were of good reproducibility, and nice polymorphism. Almost equal number of bands were seen across three trials.

\section{Molecular profiling of rice genotype with reproducible RAPD markers}

As far as the results are concerned, it was found that the primers B-12 and B-1 are quite reproducible.

\section{Primer B12}

TRIAL 1 


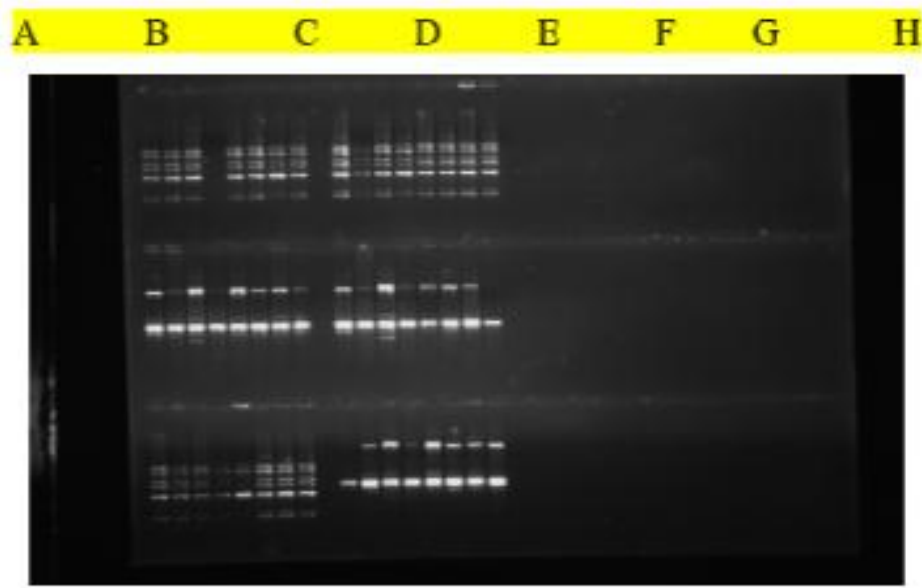

Fig5. Molecular profiling of AFM 19A1was done using B12 Primer. On an average 3 bands were produced for each isogenic line

Table3. Number of bands in total across all 3 cultivars and their reproducibility in Isogenic samples

\begin{tabular}{|c|c|c|c|c|}
\hline \multirow[t]{2}{*}{ Primer } & \multicolumn{2}{|c|}{$\begin{array}{l}\text { Total No of bands in } \\
\text { 19A across all } 3 \text { lines }\end{array}$} & trials for INDAM & \multirow[b]{2}{*}{ Reproducibility } \\
\hline & Trail1 & Trail 2 & Trail 3 & \\
\hline OPF-03 & 35 & 29 & 23 & LOW \\
\hline OPB-12 & 31 & 30 & 29 & HIGH \\
\hline OPB-01 & 20 & 10 & 16 & LOW \\
\hline
\end{tabular}

It was revealed that the presence of non-parental band(s) is a supplementary evidence for co dominancy of the markers (Wu et al., 2002). Similar features were also reported in other markers and plants via RAPD co dominant markers in soybean (Zhang et al., 1995), rice (Wu et al., 2002), Chrysanthemum hybrids (Huang et al., 2000) and SSR markers in maize heterozygous DH lines (Hollingsworth et al., 1998). The presence of slower migrating heteroduplex DNA is, therefore, useful for detection of heterozygous individuals.

The reproducibility problem of RAPD-PCR can be overcome, in principle, by using rigid laboratory protocols and doing repeatability tests. The purpose of such tests is to repeat the analyses and retain only the bands that appear in both initial and later screenings for further analyses (Thorman et al., 1994; Schwengel et al., 1994). A procedure to optimize repeatability and avoid bias.

Greater and greater amounts of sequence data, genomic and cDNA libraries, and isolated chromosomes will be increasingly available with time. This information and material will be of major importance in the future due to the present rate of extinction and diversity reduction. For example, they could be used to draw genes coding for potentially useful traits. Data obtained through PCR analysis of DNA fragments from ancient DNA samples have shown evolutionary changes within the gene pool over long time periods. The information available is now also key in devising suitable conservation strategies. It is highly unlikely, however, that these data and molecular sample collections can replace the germplasm conservation of whole organisms. Most agronomically important characters are coded by polygenes, and it would be virtually impossible, to reconstitute all the implied gene blocks with their regulatory elements.

\section{REFERENCES}

[1] Hollingsworth WO, Christie CB, Nichols MA, Neilson HF (1998). Detection of variation among and within asparagus hybrids using random amplified DNA (RAPD) markers. Elsevier Science Publishers. 15.11:26.

[2] Huang SC, Tsai CC, Sheu CS (2000). Genetic analysis of Chrysanthemum hybrids based on RAPD molecular markers. Bot. Bull Acad. Sin. 41-257:262.

[3] Jones CJ, Edwards KJ, Castaglione S, Winfield MO, Sala F, Wiel C van de, Bredemeijer G, Vosman B, Matthes M, Daly A, Brettschneider R, Bettini P, Buiatti M, Maestri E, Malcevschi A, Marmiroli N, Aert R, Volckaert G, Rudea J, Linacero R, Vazquez A, Karp A (1997). Reproducibility testing of RAPD, AFLP and SSR markers in plants by a network of European laboratories. Mol Breed. 3-381:390. 
[4] Nitish K, Modi AR, Singh AS, Gajera BB, Patel AR (2010). Assessment of genetic fidelity of micropropagated date palm (Phoenix dactylifera L.) plants by RAPD and ISSR markers assay. Gene 16207:213.

[5] Schwengel DA, Jedlicka AE, Nanthakamur EJ, Weber JL, Levitt RC (1994). Comparison of fluorescencebased semi-automated genotyping of multiple microsatellite loci with autoradiographic techniques. Genomics 22: 46-54.

[6] Senthilkumar, N., G.G. Subramanium (2011). RAPD markers and their applications in plant breeding. Sciencevision. 11-116:124.

[7] Thormann CE, Ferreira ME, Camargo LEA, Tivang JG, Osborn TC (1994). Comparison of RFLP and RAPD markers to estimating genetic relationships within and among cruciferous species. Plant Mol. Bio. 33-281:298.

[8] Wu JY, Wu HK, Chung MC (2002). Co-dominant RAPD markers closely linked with two morphological genes in rice (Oryza sativa L.). Bot. Bull Acad. Sin. 43-171:180.

[9] Zhang K, Haung N, Bennet J, Khush G (1995). PCR based marker assisted selection in rice breeding. IRRI Discussion papers No.12.

Citation: Abdul Momin Raufi, "Study of Reproducibility of Rapd Markers in Rice Cultivars", International Journal of Research Studies in Agricultural Sciences (IJRSAS), vol. 6, no. 3, pp.36-40, 2020. Available: DOI: http://dx.doi.org/10.20431/2454-6224.0603005

Copyright: () 2020 Authors. This is an open-access article distributed under the terms of the Creative Commons Attribution License, which permits unrestricted use, distribution, and reproduction in any medium, provided the original author and source are credited. 